\title{
Total population survey of the frequency and severity of asthma in 17 year old boys in an urban area in Israel
}

\author{
Ilan Auerbach, Chaim Springer, Simon Godfrey
}

\begin{abstract}
Background There is evidence that the prevalence of asthma in children and young people is increasing.

Methods An examination of a total population (35 170) of 17 year old Jewish boys of one seaside urban area in Israel was undertaken during two years, 1986 and 1990, by trained respiratory physicians in a regional recruiting office of the Israel Defence Forces. All boys who had ever been diagnosed as having asthma or symptoms that could have been due to asthma underwent a further examination by respiratory physicians that included spirometry at rest. A test to evaluate exercise induced asthma was performed on a treadmill in $88 \%$ of the boys.
\end{abstract}

Results Lifetime prevalence (asthma in the past or at present) increased from $7.9 \%$ in 1986 to $9.6 \%$ in 1990 . Point prevalence (current asthma) increased from $5.0 \%$ to $5 \cdot 9 \%$. The prevalence of current asthma increased in all degrees of severity (mild disease from $3 \cdot 3 \%$ to $3 \cdot 7 \%$, moderate disease from $1 \cdot 7 \%$ to $2 \cdot 2 \%$, and severe disease from $0.03 \%$ to $0.04 \%$ ). By the age of $17,77 \cdot 4 \%$ of boys who had suffered from asthma had no or only very mild symptoms.

Conclusions It is considered that the measured increase in prevalence of asthma from 1986 to 1990 reflects a true increase among the Jewish Israeli population.

\section{(Thorax 1993;48:139-141)}

Asthma is one of the most common chronic diseases of childhood and adolescence. There is evidence that the prevalence of asthma in children and young people has increased significantly in the second half of this century all over the world.$^{1-7}$ In many countries the rates of admission to hospital, severity, mortality, and sales of drugs for asthma have increased greatly..$^{8-12}$ There are, however, significant worldwide differences in the prevalence of asthma. The highest rates are found in Australia and New Zealand, medium rates are found in North America and Europe, and the lowest rates are found in third world countries. ${ }^{13-15}$ The reasons for these differences and the increases in morbidity and mortality over the past decades are not completely known. Some of them may be related to changes in exposure to air pollution, climatic changes, and allergens, including many kinds of pollens, dust mites, moulds, and parasites. ${ }^{16-21}$

Many of the studies on the prevalence of asthma have suffered from technical epidemiological problems. ${ }^{22}$ Some used questionnaires administered to lay people as the basis for diagnosing asthma and others involved only small selected samples of the population. In Israel, all 17 year old boys are examined by trained physicians in the recruiting offices of the Israel Defence Forces to determine their suitability for obligatory military service. We have used the availability of a large and totally unselected population of 17 year old boys to examine the prevalence of previous and present asthma.

\section{Subjects and methods}

The population investigated comprised all 17 year old boys in one seaside urban area of Israel who attended the Israel Defence Forces recruiting office during two years-1986 and 1990. All 17 year old Israeli nationals are obliged by law to attend for examination. (The only exceptions are the few permanently institutionalised patients and the severely handicapped, for whom a full medical report is obtained from the treating physician.) Hence it was possible to obtain information on the medical state of these 17 year old citizens, who comprised $95.5 \%$ of the total male population of this age in this region of the country. ${ }^{23} \mathrm{Girls}$ were not included because some opt out of military service for religious reasons and hence their population was not complete. A total of 13363 consecutive boys were examined during 1986 and 21807 during 1990.

Exactly the same methods of evaluation were used in the two years. The subjects were asked specifically whether they had ever been diagnosed as having asthma (or "spastic bronchitis," which is a common synonym for asthma in Israel), and whether they had ever suffered from recurrent wheezing, from nocturnal cough, or from cough or wheeze after exertion. All boys who gave a positive reply to any of these questions, which implies the possibility of asthma in the past or present, were referred for a second examination by a trained respiratory physician. Subjects were instructed not to take any medication for asthma on the day of the second examination. 
The second examination included a further detailed history, physical examination, and spirometry at rest. All boys except those with overt clinical signs and spirometric evidence of severe airway obstruction also underwent an exercise test. The test comprised six minutes of treadmill running at a speed of 5 kilometres/ hour and an incline of $10^{\circ}$ while they were breathing room air $\left(22^{\circ} \mathrm{C}, 50 \%\right.$ relative humidity). Lung function was measured at five and 10 minutes after the exercise to determine the percentage fall in forced expiratory volume in one second $\left(\mathrm{FEV}_{1}\right)$.

As a result of these examinations, the subjects were divided into the following categories:

(1) Asthma in total remission for at least three years with normal spirometry $\left(\mathrm{FEV}_{1}\right.$ more than $70 \%$ of the predicted value) and a normal response to exercise (decrease in $\mathrm{FEV}_{1}$ after exercise of less than $10 \%$ ).

(2) Mild, infrequent asthma requiring only irregular treatment with inhaled $\beta_{2}$ agonist or a fall in $\mathrm{FEV}_{1}$ after exercise of less than $20 \%$ and $10 \%$ or more.

(3) Moderate persistent asthma requiring regular medication or prophylaxis with slow release theophylline, sodium cromoglycate, or inhaled corticosteroids, $\mathrm{FEV}_{1}$ at rest at least $50 \%$ predicted, or a fall in $\mathrm{FEV}_{1}$ after exercise of $20 \%$ or more.

(4) Continuous severe asthma requiring steroid prophylaxis for control and with FEV at rest less than $50 \%$ predicted.

These data were recorded on a computer and were used for analysis. Comparison between groups was performed by $\chi^{2}$ analysis.

\section{Results}

A total population of 35170 boys 17 years of age was examined during 1986 and 1990. Figure 1 shows the results. Lifetime prevalence (a history compatible with asthma at any time) increased from $7.9 \%$ in 1986 to $9.6 \%$ in 1990 ( $p<0.0001$ ). Point prevalence (current asthma) increased from $5.0 \%$ in 1986 to $5.9 \%$ in 1990 ( $\mathrm{p}<0.005)$.

Figure 2 shows the distribution among the three severity subgroups in the boys with current asthma. The prevalence of mild asthma increased from $3.3 \%$ in 1986 to $3.7 \%$ in 1990 $(\mathrm{p}=0.06)$, moderate asthma from $1.7 \%$ in 1986 to $2.2 \%$ in 1990 ( $\mathrm{p}<0.005)$, and severe asthma from $0.03 \%$ in 1986 to $0.04 \%$ in 1990 (NS).

Figure 1 Lifetime prevalence (open columns) and point prevalence (hatched columns) of asthma among 13363 boys aged 17 in 1986 and 21807 boys aged 17 in 1990. Both lifetime prevalence and point prevalence increased significantly from 1986 to 1990.

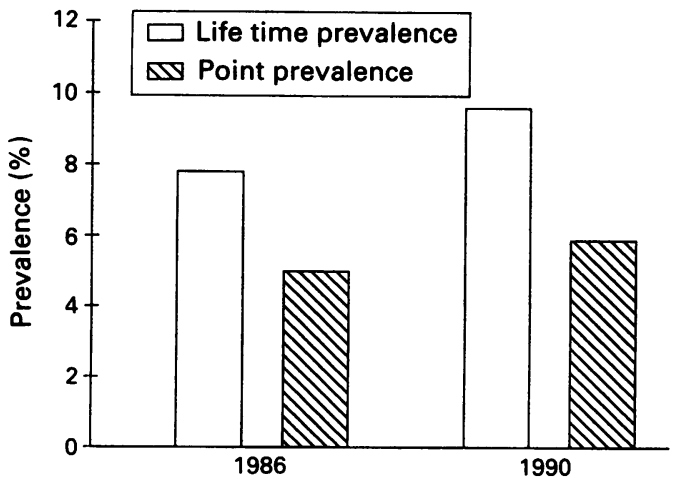

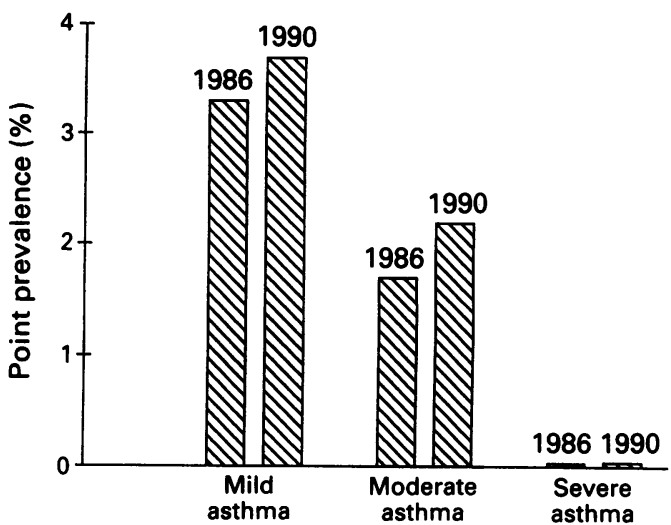

Figure 2 Point prevalence of asthma among 35170 boys aged 17 during 1986 and 1990 according to the severity of the disease.

Among the 3148 boys with a positive past or present history of asthma during 1986 and $1990,1189(38 \%)$ had been in total remission for at least three years, $1248(40 \%)$ still suffered from mild asthma, $749(24 \%)$ from moderate asthma, and $12(0 \cdot 4 \%)$ from severe asthma at age 17.

\section{Discussion}

This survey of virtually the total 17 year old male population of one region of Israel during 1986 and 1990 has shown an increase in incidence of asthma similar to that in other developed countries. The conclusions are strengthened by the large numbers involved, the completeness of the population surveyed, and the objective method used.

There are a number of problems that can affect surveys of the prevalence of asthma, including population selection and methods used for diagnosis. In the present study our male population was unselected and complete. Diagnosis of asthma by only one method-for example, questionnaires, clinical examination, tests of lung function, or bronchial reactivitycan be faulted in that a positive response may select a unique group or it may be negative in the intervals between the attacks. ${ }^{24-26} \mathrm{We}$ therefore chose to use a combination of clinical and laboratory methods in an attempt to avoid over or underestimation of the prevalence of asthma and exactly the same methods for evaluation were used in the two years of the survey. The only subjects who were excluded from the exercise challenge were those with poor lung function at rest (FEV less than $70 \%$ predicted). These boys were regarded as having at least moderate disease and comprised $12 \%$ of the total.

In the present study we showed that lifetime prevalence increased from $7.9 \%$ in 1986 to $9.6 \%$ in 1990 (an average increase of $5.0 \%$ a year). Current asthma increased from $5.0 \%$ to $5.9 \%$ (an increase of $4.2 \%$ a year). The total number of recruits examined increased from 13363 in 1986 to 21807 in 1990. Careful inspection of the records showed this to be due to the incorporation of additional suburbs in 1987 and to an influx of new immigrants, principally from the former Soviet Union, in 
1990. During the three years 1987 to 1989 inclusive, the population was stable at around 18000 and a separate analysis of these three years showed similar trends in prevalence of asthma, with, if anything, a tendency to an even greater increase. Similar increases in prevalence were reported by Burr and colleagues, ${ }^{5}$ who found an increase in lifetime prevalence of asthma from $6 \%$ in 1973 to $12 \%$ in 1988 (an average increase of $4.7 \%$ a year); current asthma increased from $4 \%$ to $9 \%$ (increase of $5.6 \%$ a year). The point prevalence rate in our present study was a little higher than the $6 \%$ reported in 1980 for 17 year old American boys ${ }^{2}$ but much higher than the $1.8 \%$ reported in Finland during $1989 .{ }^{27}$

There is some evidence that the frequency of severe asthma is increasing. ${ }^{11}$ The percentage of severe asthma in the present study was small: $0.03 \%$ in 1986 and $0.04 \%$ in 1990 . These figures are considerably smaller than those reported in the United Kingdom $(0.5 \%)^{10}$ and in Australia $(0.8 \%){ }^{24}$ This may be due to differences in the criteria used to determine severity. In the United Kingdom study severity was assessed by an interview and in the Australian study by bronchial reactivity to inhaled histamine. Both methods might have overestimated severity. In our present study severe asthma was diagnosed in subjects who had severe persistent airflow obstruction despite steroid prophylaxis. Alternatively, these results can be taken to indicate that severe asthma in Israel is less frequent than in the United Kingdom and Australia. The mean remission rate of asthma in the present study was $38 \%$, which is similar to the reported remission rates of $10-14 \% .^{28-30}$

Two potential problems in the present study may bias the prevalence rates. Firstly, conscripts may not have revealed that they suffer from asthma because this may have precluded service in a combat unit or they may simply have forgotten that they had asthma in early childhood. To investigate this possibility we sought information on the number of conscripts who were found to have asthma after their induction into the Defence Forces, but who had not been diagnosed at the time of the examination in the recruiting office. Only $0.3 \%$ of the total conscripts had previously undiagnosed asthma. Secondly, conscripts may claim they suffer from asthma so as not to serve in a combat unit. This potential bias was minimised with the combination of methods discussed earlier.

In conclusion, we have shown that nearly $10 \%$ of boys in Israel have suffered from asthma by the age of 17 although only about $24 \%$ of these asthmatic boys still require regular prophylactic medication at this age. The study has also shown a significant increase in the incidence of asthma from 1986 to 1990 of about $4.3 \%$ a year.
We thank all the primary physicians and the respiratory physicians who participated in the examination of the conscripts. We also thank the Medical Corps of the Israel Defence Forces, which provided the data for this study.

1 Burr ML. Is asthma increasing? J Epidemiol Community Health 1987;41:185-9.

2 Gergen PG, Mullally DI, Evans R III. National survey of prevalence of asthma among children in the United States, 1976 to 1980 . Pediatrics $1988 ; 81: 1-7$.

3 Fleming DM, Crombie DL. Prevalence of asthma and hay fever in England and Wales. BMJ 1987;294:279-83.

4 Ellul-Micallef $\mathrm{R}$, Al-Ali S. The spectrum of bronchial asthma in Kuwait. Clin Allergy 1984;14:509-17.

5 Burr ML, Butland BK, King S, Vaughan-Williams E. Changes in asthma prevalence: Two surveys 15 years apart. Arch Dis Child 1989;64:1452-6.

6 Anderson HR. Is the prevalence of asthma changing? Arch Dis Child 1989;64:172-5.

7 Burney PGJ, Chinn S, Rona RJ. Has the prevalence of asthma increased in children? Evidence from a National study of health and growth in 1973-86. BMJ 1990;300: 1306-10.

8 Halfon N, Newacheck PW. Trends in hospitalization for acute childhood asthma, 1970-1984. Am J Public Health 1986;67:1308-11.

9 Mitchell EA, Anderson HR, Freeling P, White PT. Why are the hospital admission and mortality rates for childhood asthma higher in New Zealand than in the United Kingdom? Thorax 1990;45:176-82.

10 Woolcock AJ. Worldwide differences in asthma prevalence and mortality. Chest 1986;90(suppl 5):40-5.

11 Anderson HR. Increase in hospital admissions for childhood asthma: trends in referral, severity, and readmissions from 1970 to 1985 in a health region of the United Kingdom. Thorax 1989;44:614-9.

12 Keating G, Mitchell EA, Jackson R, Beaglehole R, Rea H. Trends in sales of drugs for asthma in New Zealand, Australia, and the United Kingdom, 1975-81. BMJ 1984; 289:348-51.

13 Gregg I. Epidemiological research in asthma: The need for a broad perspective. Clin Allergy 1986;16:17-23

14 Cookson JB. Prevalence rates of asthma in developing countries and their comparison with those in Europe and North America. Chest 1987;91(suppl 6):97-103.

15 Jones DT, Sears MR, Holdway MD, Hewitt CJ, Flannery EM, Herbison GP, et al. Childhood asthma in New Zealand. Br J Dis Chest 1987;81:332-40.

16 Charpin D, Vervolet D, Charpin J. Epidemiology of asthma in Western Europe. Allergy 1988;43:481-92.

17 Goren AI, Hellman S. Prevalence of respiratory symptoms and diseases in school children living in a polluted and in a low polluted area in Israel. Environ Res $1988 ; 45: 28-37$.

18 Burney $P$. Why study the epidemiology of asthma? (editorial). Thorax 1988;43:425-8.

19 Hendrick DJ. Asthma: epidemics and epidemiology (editorial). Thorax 1989;44:609-13.

20 Glazer I. Epidemiology of bronchial asthma in the Middle East. Ann Allergy 1988;61:312-4.

21 Colin A, Said E, Winter S. Exercise induced asthma in school children: A pilot study in two Haifa districts. Isr J Med Sci 1985;21:40-3.

22 Woolcock AJ. Epidemiologic methods for measuring prevalence of asthma. Chest 1987;91(suppl 6):89-92.

23 Sicton M. Statistical abstract of Israel. Jerusalem: Central Bureau of Statistics, 1987;38:34-5.

24 Anderson HR, Bland JM, Patel S, Peckham C. The natural history of asthma in childhood. J Epidemiol Community Health 1986;40:121-9.

25 Enarson DA, Vedal S, Schulzer M, Dybuncio A, ChanYeung $M$. Asthma, asthmalike symptoms, chronic bronchitis, and the degree of bronchial hyperresponsiveness in epidemiologic surveys. Am Rev Respir Dis 1987;136. 613-7.

26 Samet JM. Epidemiologic approaches for the identification of asthma. Chest 1987;91(suppl 6):74-8.

27 Haahtela T, Lindholm H, Bjorksten F, Koskenvuo K Laitinen LA. Prevalence of asthma in Finnish young men. BMJ 1990;301:266-8.

28 Freeman GL, Johnson S. Allergic diseases in adolescents. Am J Dis Child 1964;107:560-6.

29 Rackemann FM, Edwards MC. Asthma in children. A follow up of 688 patients after an interval of twenty years. follow up of 688 patients after an in

30 Dodge RR, Burrows $B$. The prevalence and incidence of asthma and asthma-like symptoms in a general population sample. Am Rev Respir Dis 1980;122:567-75. 